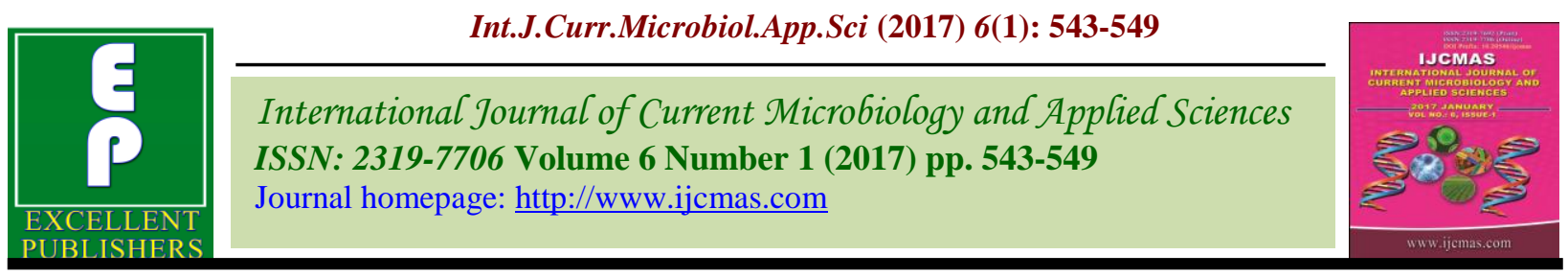

Original Research Article

http://dx.doi.org/10.20546/ijcmas.2017.601.067

\title{
Multidrug Resistance Pattern in Confirmed Cases of Catheter Associated Urinary Tract Infection in a Tertiary Care Hospital: A Prospective Study
}

\author{
Shilpa ${ }^{1}$ and G.P. Aaftab ${ }^{2} *$ \\ ${ }^{1}$ Medanta Mediciti, Gurgaon, India \\ ${ }^{2}$ Navodaya Medical College Hospital and Research Centre, Raichur, India \\ ${ }^{*}$ Corresponding author:
}

\begin{tabular}{|c|c|}
\hline & A B S T R A C T \\
\hline $\begin{array}{l}\text { CAUTI; Incidence } \\
\text { rate; Antimicrobial } \\
\text { resistance; } \\
\text { Preventive bundle. }\end{array}$ & \multirow{4}{*}{$\begin{array}{l}\text { One of the most common infections acquired by patients in health care facilities is the } \\
\text { Urinary tract infection attributed to the use of an indwelling urinary catheter. Catheter- } \\
\text { acquired urinary tract infection (CAUTI) is the source for about } 20 \% \text { of episodes of health- } \\
\text { care acquired bacteremia in acute care facilities. The growing Drug resistance developed } \\
\text { by the uropathogens from CAUTI cases throws a therapeutic challenge to the clinicians. } \\
\text { To determine the CAUTI rate and the antibiotic susceptibility patterns exhibited by the } \\
\text { uropathogens causing CAUTI. Urine Samples aseptically aspirated from the sampling port } \\
\text { of the urinary catheter were collected from catheterised patients and were processed using } \\
\text { conventional culture method as per standard protocol. A total } 12 \text { episodes of CAUTI } \\
\text { occurred in } 720 \text { catheterised patients, amounting to a CAUTI rate of } 3.33 \text { per } 1000 \text { catheter } \\
\text { days. The most common uropathogens isolated were E.coli and Staphylococci, followed } \\
\text { by Klebsiella pneumonia. In ur study, we observed that } 66 \% \text { of the Gram negative bacilli } \\
\text { isolated from confirmed CAUTI cases were ESBL and AmpC producers. Strict adherence } \\
\text { to hand hygiene and the preventive bundle helps in reducing the CAUTI rates drastically } \\
\text { and curb the nuisance of spread of multi drug resistance hospital acquired infections. }\end{array}$} \\
\hline Article Info & \\
\hline $\begin{array}{l}\text { Accepted: } \\
\text { xx December } 2016 \\
\text { Available Online: } \\
\text { xx January } 2017\end{array}$ & \\
\hline & \\
\hline
\end{tabular}

\section{Introduction}

Health-care associated infections (HAIs) have become a global patient safety concern (Mathur et al., 2015). Device-associated infections (DAIs) account for the majority of these infections. DAIs have tremendous implications in terms of associated mortality, morbidity, increased cost of treatment, adverse patient outcomes and social impact. Apart from the escalating rates, HAIs are now increasingly being caused by multi-drugresistant organisms, which are difficult to treat due to paucity of new antimicrobials.

Catheter Associated Urinary Tract Infection (CAUTI) is a major cause of hospital acquired
Bacteraemia (Parida et al., 2013). Upto 25\% of hospitalised patients undergo urinary catheterisation. Although often necessary intervention, indwelling catheters are a leading cause of device associated infection. The most common microorganisms involved in Device associated nosocomial infections are those belonging to Enterobacteriaceae family, Acinetobacter species, Pseudomonas species, Staphylococcus aureus, and Coagulase Negative Staphylococci (Mehta et al., 2007; Kanj et al., 2012). Multiple risk factors are associated with causation of CAUTI. Bio film formation in catheters has 
not only been implicated as an important factor involved in device related infection but also confers resistance to antimicrobial treatment. Additional risk factors include female sex, older age and not maintaining a closed drainage system (Lo et al., 2014).

Over the past several decades, the frequency of antimicrobial resistance and its association with serious infectious diseases have increased at alarming rates. Extensive antibiotic resistance has been observed in GNB. Antibiotic resistance develops through different mechanisms, such as the alteration of the drug target and drug inactivation by enzymes (Pawar et al., 2008). Production of Extended $\quad$ spectrum $\quad \beta$-lactamases (ESBL),Amp C $\beta$ lactamases (AmpC) and metallo $\beta$ lactamases (MBL) are responsible for multidrug resistance of these pathogens.

The present study has been undertaken to determine CAUTI rate, in Intensive Care Units of our hospital, a tertiary care government hospital, Karnataka Institute of Medical Sciences Hospital(KIMSH), Hubballi, to identify the infectious agents involved and their antibiotic resistance profiles during the period between December 2013and December 2014.

\section{Materials and Methods}

Urine Samplesaseptically aspirated from the sampling port of the urinary catheter were collected fromcatheterised patients admitted in different Intensive Care Units such as Medical, Surgical, Orthopedic, Paediatrics, Neoanatal and Obstetrics Intensive Care Units (ICU) of Karnataka Institute of Medical Sciences Hospital, Hubballi and were transported immediately to the laboratory in a sterile container.

Inclusion criteria: Patients admitted to the ICUs having hospital acquired infection which is defined as an infection that is identified at least 48 to 72 hours following admission associated with Urinary catheter.

Exclusion criteria: Patients having infection at the time of or prior to hospitalization.

\section{Processing in the laboratory}

All the samples were processed using conventional culture method as per standard protocol (Clinical and laboratory Standards Institute, 2012). The unspun urine was subjected to gram stain, wet mount for the presence of pus cells and organisms. With the calibrated loop urine was cultured on blood agar media for quantitative analysis to assess the microbial counts. MacConkey agar media was also plated. The significant bacteriuria of $10^{5} \mathrm{cfu} / \mathrm{ml}$ was taken into consideration while confirmation as CAUTI. The identification and antibiotic sensitivity was done by the disc diffusion test as recommended by CLSI guidelines.

Screening test for ESBL production was done using Ceftazidime disks. A zone diameter of $\leq$ $22 \mathrm{~mm}$ was considered as probable ESBL producer, which was confirmed by Phenotypic confirmatory disc diffusion test using Ceftazidime and Ceftazidime+Clavulanic acid (CLSI, 2013).

Isolates were screened for $\mathrm{AmpC}$ production using Cefoxitin disk. Isolates with Cefoxitin zone of $<18 \mathrm{~mm}$ were considered as screen positives. Phenotypic confirmation of AmpC beta-lactamase was done by using AmpC disk test (Singhal et al., 2005). Screening test for MBL production was doneusing Imipenem disk. Isolates with zone of $<19 \mathrm{~mm}$ were considered as screen positive and were subjected to Imipenem-EDTA Combined disk test for Phenotypic confirmation Isolates were screened for KPC production using Ertapenem disk. Isolates with Ertapenem zones $\leq 21 \mathrm{~mm}$ were considered as screen positive. 
Phenotypic confirmatory test for KPC production was done using Modified Hodge Test (MHT) (CLSI, 2013).

Isolates were screened for MRSA productionby Cefoxitin disc diffusion method.Zone size was interpreted according to CLSI criteria: susceptible, $\geq 22 \mathrm{~mm}$; resistant, $\leq 21 \mathrm{~mm}$.

\section{Calculation of CAUTI rate}

CAUTI rates per 1000 device days were calculated by dividing the total number of catheter associated infection by the total number of device days and multiplying the result with 1000 .

Statistical analysis: Statistical analysis was done by Fischer's Exact test using SPSS software and test of proportions wherever applicable.

\section{Results and Discussion}

During the study period of one year, 720 patients were treated by indwelling catheter, of which 12 patients developed urinary tract infection. The total urinary catheter days amounted to 3600 in the study population. A total 12 episodes of CAUTI occurred in these patients, amounting to a CAUTI rate of 3.33 per 1000 catheter days. The different organisms isolated were Escherichia coli 3 (25\%), Staphylococcus species 3 (25\%), Klebsiella pneuomoniae 2(16.66\%), Acinetobacer baumanii 2(16.66\%) and Pseudomonas aeruginosa 2(16.66\%) as shown in Table 1.

Based on the screening tests and confirmatory tests conducted to determine the drug resistance mechanisms, we observed that, out of the total 12 CAUTI cases, 9 were caused by Gram negative bacteria, of which 6 $(66.66 \%)$ were ESBL producing infections, 6
(66.66\%) were AmpC producers and 4 (44.44\%) were Co-producers of both ESBL and AmpC. Among the total 4 Pseudomonas aeruginosa and Klebsiella pneumoniae isolated, $1(25 \%)$ was MBL producer. None of the Klebsiellae were KPC producers (Tables 2 and 3).

Among Staphylococci, none of the isolates recovered from urine samples of CAUTI were Methicllin resistant Staphylococcus aureus (MRSA). However, out of the 2 CoNS, 1 was detected to be MR CoNSby cefoxitin disc diffusion test (Table 4).

Of the total 12 cases of CAUTI, most recovered while 2 deaths occurred, the mortality rate being $16.66 \%$, which was found to be significant using Fischer's test (Table $5)$.

The pathogens isolated from CAUTI patients showed multi drug resistance. The ESBL and AmpC beta lactamase producing organisms were almost unanimously resistant to ampicillin,cefazolin, cefotaxime, ceftriaxone, cefepime and tetracycline. The most effective antibiotic was Imipenem followed by amikacin for the Gram negative isolates. The S.aureuswere resistant to ampicillin and ciprofloxacin. All the staphylococci isolates were sensitive to azithromicin, clindamicin, linezolid and vancomycin. The overall resistance pattern of the pathogens isolated from the CAUTI patients is given below in Table 6.

Nosocomial infections are one of the most important causes of mortality and morbidity as well as of the increase in health expenditures. It has been reported that ICUs account for $25 \%$ of nosocomial infections (Rosenthal et al., 2006). Maximum number of patients were admitted in ICU due to severe injury by Road traffic accidents. Severely traumatized patients due to road traffic 
accidents are usually on multiple devices and present therapeutic challenges due to their inability to move. Through this study, an attempt has been made to assess the Catheter associated urinary tract infection (CAUTI) rate, in different Intensive Care Units of our hospital, to identify the infectious agents involved and their antibiotic resistance profiles during the period between December 2013 to December, 2014.

In our study the catheter associated urinary tract infection (CAUTI) rate in 1000 urinary catheter days was found to be 3.33. Our study showed a lower CAUTI rate as compared with the study conducted by Rosenthal VD et al in 8 developing countries which found the CAUTI rate to be 8.9 per 1000 catheter days. However, a study conducted by Mehta et al., at seven Indian studies found CAUTI rates to be much lower at 1.41 per 1000 catheter days.
The lower CAUTI rate at our institute could be attributed to the trained staff who are regularly updated with infection prevention practices like aseptic techniques, close drainage system, placement of urobag below the waist, catheter care and a strict adherence to hand hygiene protocol.

The different organisms isolated were Escherichia coli 3 (25\%), Staphylococcus 3 (25\%), Klebsiella pneuomoniae 2(16.66\%), Acinetobacer baumanni 2(16.66\%) and Pseudomonas aeruginosa 2(16.66\%). In accordance with our study, the study conducted by Guanche-Garcell et al., also found that E.coli $(53.8 \%)$ was the most predominant organism associated with CAUTI followed by coagulase negative Staphylococci $(23.1 \%)$ and Klebsiellaspp (15.4\%).

Table.1 Isolated organisms from CAUTI patients

\begin{tabular}{|c|c|c|c|c|}
\hline Sr no & Category & Number $(\%)$ & \multicolumn{2}{|c|}{ Organism Number $(\%)$} \\
\hline \multirow[t]{4}{*}{1} & \multirow[t]{4}{*}{ GNB } & \multirow[t]{4}{*}{$9(75 \%)$} & Escherichia coli & $3(25 \%)$ \\
\hline & & & Klebsiella pneumoniae & $2(16.66 \%)$ \\
\hline & & & Acinetobacter baumanii & $2(16.66 \%)$ \\
\hline & & & Pseudomonas aeruginosa & $2(16.66 \%)$ \\
\hline \multirow[t]{2}{*}{2} & \multirow[t]{2}{*}{ GPC } & \multirow[t]{2}{*}{$3(25 \%)$} & Staphylococcus aureus & $1(8.33 \%)$ \\
\hline & & & $\begin{array}{l}\text { Coagulase negative } \\
\text { Staphylococci }\end{array}$ & $2(16.66 \%)$ \\
\hline
\end{tabular}

Table.2 ESBL, AmpC and Co-producers

\begin{tabular}{|l|l|l|l|l|l|}
\hline Specimen & $\begin{array}{l}\text { Total } \\
\text { number of } \\
\text { specimen }\end{array}$ & $\begin{array}{l}\text { Total no of } \\
\text { GNB }(\boldsymbol{\%})\end{array}$ & $\begin{array}{l}\text { ESBL } \\
\text { positive no } \\
(\boldsymbol{\%})\end{array}$ & $\begin{array}{l}\text { AmpC } \\
\text { positive no } \\
(\boldsymbol{\%})\end{array}$ & $\begin{array}{l}\text { ESBL + AmpC } \\
\text { positive no (\%) }\end{array}$ \\
\hline $\begin{array}{l}\text { Urinary } \\
\text { catheter }\end{array}$ & 12 & $9(75 \%)$ & $6(66.66 \%)$ & $6(66.66 \%)$ & $4(44.44 \%)$ \\
\hline
\end{tabular}

Table.3 MBL producing isolates obtained from CAUTI urine samples

\begin{tabular}{|l|l|l|}
\hline Specimen & $\begin{array}{l}\text { Total no of Pseudomonas } \\
\text { and Klebsiella }\end{array}$ & MBL positive (\%) \\
\hline Urinary catheter & 4 & $1(25.0 \%)$ \\
\hline
\end{tabular}


Table.4 Methicillin resistance detected in Staphylococci isolated from CAUTI samples

\begin{tabular}{|l|l|l|}
\hline Specimen & S.aureus & CoNS \\
\hline Urinary catheter & 1 & 2 \\
\hline MRSA & 0 & - \\
\hline MRCoNS (\%) & - & $1(50 \%)$ \\
\hline
\end{tabular}

Table.5 Mortality rate observed in the CAUTI cases

\begin{tabular}{|l|l|l|l|l|}
\hline Devices & Fatal Cases & $\begin{array}{c}\text { Non Fatal } \\
\text { Controls }\end{array}$ & Z value & P value \\
\hline CAUTI & 2 & 10 & 1.548 & $0.05(\mathrm{~S})$ \\
\hline
\end{tabular}

Table.6 Resistance pattern of isolates from CAUTI patients

\begin{tabular}{|c|c|c|c|c|c|c|c|c|c|c|c|c|c|c|}
\hline \multirow[t]{2}{*}{ Organism } & \multicolumn{14}{|c|}{ Resistance pattern (\%) } \\
\hline & $\mathrm{Ak}$ & Amp & Amc & $\mathrm{Cz}$ & $\mathrm{Cpm}$ & $\mathrm{Cx}$ & Ctx & $\mathrm{Caz}$ & $\mathrm{Ctr}$ & Cip & Cot & Gen & $\operatorname{Imp}$ & $\mathrm{Te}$ \\
\hline E.coli & 34 & 100 & 63 & 100 & 100 & 67 & 67 & 67 & 67 & 77 & 85 & 46 & 00 & 92 \\
\hline K.pneumoniae & 55 & 100 & 68 & 100 & 100 & 67 & 67 & 67 & 67 & 88 & 88 & 62 & 00 & 83 \\
\hline Pseudomonas & 66 & 100 & 100 & 100 & 100 & 100 & 100 & 100 & 100 & 100 & 100 & 66 & 25 & 100 \\
\hline Acinetobacter sp & 100 & 100 & 100 & 100 & 100 & 100 & 100 & 100 & 100 & 100 & 100 & 100 & 00 & 100 \\
\hline
\end{tabular}

Antimicrobial resistance represents a major problem in the management of hospital acquired infection. The uropathogens isolated from CAUTI patients were multidrug resistant. These findings correlate with various other studies (Raka et al., 2004). Among the variety of mechanisms that can provide resistance to $\beta$-lactam antibiotics in Gram-negative bacilli, the production of $\beta$ lactamase is by far the single most important factor. Biofilm formation is inherently associated with device associated infections and contributes to antimicrobial resistance. Among Gram negative bacilli 6(66.66\%) were ESBL producers, 6(66.66\%) Amp C producers, 4(44.44\%) were ESBL and AmpC Coproducers . Among Klebsiella pneumoniae and Pseudomonas aeruginosa1 (25\%) MBL producers. None of the Klebsiella pneumoniae isolates were KPC producers. A study conducted by Mehta et al., in ICU of seven Indian cities found that $46.4 \%$ of all Health Care Associated Infections (HCAI) were caused by Enterobacteriaceae, of which
74.1\% were ESBL producers. $27.3 \%$ of HCAI were caused by Pseudomonas spp, of which 42.0\% were MBL producers. Among the Staphyloocci isolated, only 1 CoNS was identified as Methicillin resistant. Some of the studies have reported very high rate of MRSA 84\% Mehta Rosenthal et al., conducted a study in intensive care units of seven Indian hoaspitals, found that overall $87.5 \%$ of all Staphylococcus aureus HCAIs were caused by methicillin-resistant strains.

Multidrug resistance acquired by the uropathogens makes it difficult to treat them with limited available antibiotics proving to be effective. Therefore, prevention of CAUTI itself can help in reducing the chances of transmission of these multi drug resistant bugs. Indwelling catheters are responsible for $70 \%-80 \%$ of catheter associated urinary tract infection. Significant reductions in rates of catheter-associated urinary tract infection (CAUTI) following the introduction of infection surveillance and control programs 
have been reported (Franco et al., 2007). Approaches to prevention include avoidance of indwelling catheter use which is the single most important intervention, policies for catheter insertion and maintenance, which include appropriate hand hygiene, aseptic techniques, barrier precautions, closed drainage system etc, catheter selection (smallest gauge catheter possible), surveillance of CA-UTI and catheter use, and recommendations for quality indicators. This study showed that by adhering strictly to the preventive bundle, it might be possible to bring down the CAUTI rates considerably.

\section{References}

Behera, B., Mathur, P., Das, A., Kapil, A., Sharma, V. 2008. An evaluation of four different phenotypic techniques for detection of metallo-beta-lactamase producing Pseudomonas aeruginosa. Indian J. Med. Microbiol., 26(3): 233237.

Clinical and laboratory Standards Institute. 2012. Performance standards for antimicrobials susceptibility testing. Twenty-second informational Supplement, 50.

Guanche-Garcell, H., Requejo-Pino, O., Rosenthal, V.D., Morales-Perez, C., Delgado-Gonzalez, O., FernandezGonzalez. D. Device-associated infection rates in adult intensive care units of Cuban university hospitals: International Nosocomial Infection Control Consortium (INICC) finding.

Higuera, F., Rangel-Frausto, M.S., Rosenthal, V.D., Soto, J.M., Castanon, J., Franco, G. et al. Attributable Cost and Length of Stay for Patients With Central Venous Catheter-Associated Bloodstream Infection in Mexico City Intensive Care Units: A Prospective, Matched Analysis. Infection Control and Hospital Epidemiol., 28(1): 31-35.
Joseph, N.M., Sistla, S., Dutta, T.K., Badhe, A.S., Rasitha, D., Parija, S.C. 2010. Ventilator-associated pneumonia in a tertiary care hospital in India: role of multi-drug resistant pathogens. J. Infect. Dev. Ctries., 4(4): 218-225.

Kanj, S.S., Kanafani, Z.A., Sidani, N., Alamuddin, L., Zahreddine, N., Rosenthal, V.D. 2012. International nosocomial infection control consortium findings of deviceassociated infections rate in an intensive care unit of a Lebanese university hospital, 4(1): 15-21.

Lo, E., Nicolle, L.E., Coffin, S.E., Gould, C., Maragakis, L.L. et al. 2014. Strategies to Prevent Catheter-Associated Urinary Tract Infections in Acute Care Hospitals: 2014 Update. Infection Control and Hosp. Epidemiol., 35(5): 464-479.

Mathur, P., Tak, V., Gunjiyal, J., Nair, S.A., Lalwani, S., Kumar, S. et al. 2015. device-associated infections at a level-1 trauma centre of a developing nation: Impact of automated surveillance, training and feedbacks. Indian J. Med. Microbiol., 33(1): 51-62.

Mehta, A., Rosenthal, V.D., Mehta, Y., Chakravarthy, M., Todi, S.K., Sen, N. et al. 2007. Device associated nosocomial infection rates in intensive care units of seven Indian cities. Findings of the International Nosomial infection Control Consortium (INICC). J. Hosp. Infect., 67: 168-74.

Nicolle, L.E. 2014. Catheter associated urinary tract infections. Antimicrobial Resistance and Infection Control, 3: 23.

Parida, S., Mishra, S.K. 2013. Urinary tract infections in the critical care unit: A brief review. Indian J. Critical Care Medi., 17: 370-4.

Pawar, M., Mehta, Y., Purohit, A., Trehan, N., Rosenthal, V.D. Resistance in Gram-negative bacilli in a cardiac 
intensive care unit in India: Risk factors and outcome. Annals of Cardiac Anaesthesia, 11: 20-26.

Raka, L., Mulliqi-Osmani, G., Berisha, L., Begolli, L., Omeragiq, S., et al. 2004. Etiology and susceptibility of urinary tract isolates in Kosova. Int. $J$. Antimicrob. Agents, 23 Suppl 1: S2-5.

Rosenthal, V.D., Maki, D.G., Salomao, R., Moreno, C.A., Mehta, Y, Higuera F. Device-Associated
Infections in 55 Intensive Care Units of 8 Developing Countries. Annals of Internal Med., 145(8): 582-591

Singhal, S., Mathur, T., Khan, S., Upadhyay, D.J., Chugh, S., Gaind, R. et al. 2005. Evaluation of methods for AmpC betalactamase in Gram negative clinical isolates from tertiary care hospitals. Indian J. Med. Microbiol., 23(2): 120124.

\section{How to cite this article:}

Shilpa and G.P. Aaftab. 2017. Multidrug Resistance Pattern in Confirmed Cases of Catheter Associated Urinary Tract Infection in a Tertiary Care Hospital: A Prospective Study. Int.J.Curr.Microbiol.App.Sci. 6(1): 543-549. doi: http://dx.doi.org/10.20546/ijcmas.2017.601.067 